\title{
Neutron scattering studies of catalyst systems at the ISIS neutron spallation source
}

\author{
Martin O. Jones • Andrew D. Taylor • \\ Stewart F. Parker
}

Received: 5 August 2012/ Accepted: 29 August 2012

(C) The Author(s) 2012. This article is published with open access at Springerlink.com

\begin{abstract}
The ISIS neutron spallation facility is a worldleading centre for neutron scattering and has a formidable selection of elastic and inelastic neutron scattering instruments to study the physical properties of solids and liquids by a number of techniques that include diffraction, total scattering and molecular spectroscopy. In addition, complex sample environment apparatus may be utilized with these instruments that allows materials to be studied under controlled gas environments as a function of temperature, pressure and gas flow. Here, we discuss the application of these instruments and various sample environments to materials challenges within the field of catalysis, describe some of the more recent catalysis and catalysis-related experiments and highlight the capabilities of the ISIS facility in tackling catalytic challenges.
\end{abstract}

Keywords Neutron - Neutron diffraction - Inelastic neutron scattering $\cdot$ Catalysis

\section{Introduction}

ISIS [12], (Figs. 1, 2) is a world-leading centre for neutron scattering. The technique is applicable to a great diversity of subjects spanning condensed matter physics, engineering, materials science, chemistry and soft matter. The usefulness and generality of neutron scattering arise from the properties of the neutron, which is an uncharged particle of mass $1.00866 \mathrm{amu}$ (almost the same as the hydrogen atom ${ }^{1} \mathrm{H}, 1.00782$ ) with a magnetic moment.

M. O. Jones $(\varangle) \cdot$ A. D. Taylor · S. F. Parker

ISIS Facility, STFC Rutherford Appleton Laboratory,

Chilton, Didcot, Oxon OX11 0QX, UK

e-mail: martin-owen.jones@stfc.ac.uk
The scattering occurs from the atomic nuclei of the sample and since the nucleus of an atom is only $\sim 1 / 1,000$ of the diameter of the atom, neutrons only interact weakly with matter and are consequently highly penetrating; millimeters of steel are essentially transparent.

The nuclear scattering has a number of interesting consequences. The scattering cross section is both atom and isotope dependent and is not a monotonic function of atomic number as it is for X-ray scattering (see Research (London) 7, 257, 1954). Thus for neutron diffraction studies it is straightforward to study light elements in the presence of heavy ones, hydrogen-in-metal systems being the archetype but the precise location of oxygen in heavy metal oxides is also an exemplar. Since X-rays are scattered by electrons, bond distances are more accurate from neutron scattering data, this is particularly the case for bonds involving hydrogen, since the maximum in electron density is not located at the atomic position but is displaced toward the heavier atom. Thus $\mathrm{C}-\mathrm{H}$ and $\mathrm{O}-\mathrm{H}$ distances measured by X-ray diffraction are typically $0.1 \AA$ shorter than those measured by neutron diffraction. It is also possible to distinguish elements that are adjacent in the periodic table, thus $\mathrm{Al}^{3+}$ and $\mathrm{Si}^{4+}$, as commonly found in zeolites, have identical scattering power for X-rays (since they have the same number of electrons) but different neutron cross sections, 1.503 versus 2.167 barn $\left(1\right.$ barn $\left.=1 \times 10^{-28} \mathrm{~m}^{2}\right)$, respectively, hence providing contrast.

The most striking difference in cross section occurs for ${ }^{1} \mathrm{H}$ and ${ }^{2} \mathrm{H}$, hydrogen and deuterium: $\sigma_{\text {coh }}=1.76\left({ }^{1} \mathrm{H}\right)$, $5.59 \quad\left({ }^{2} \mathrm{H}\right)$ barn, $\sigma_{\text {inc }}=80.27 \quad\left({ }^{1} \mathrm{H}\right), \quad 2.05 \quad\left({ }^{2} \mathrm{H}\right)$ barn $\left(\sigma_{\text {coh }}=\right.$ coherent scattering cross section, $\sigma_{\text {inc }}=$ incoherent scattering cross section). Hence, hydrogen is overwhelmingly an incoherent scatterer while deuterium is primarily a coherent scatterer. Coherent scattering gives information on long range properties such as structure 
Fig. 1 Aerial view of the STFC Rutherford Appleton Laboratory, Chilton, Oxfordshire, UK. The ISIS facility is the group of buildings in the lower half of the picture with the Diamond Light Source (http://www.diamond.ac.uk) and the Research Complex (http://www.rc-harwell.ac.uk) shown in the upper half

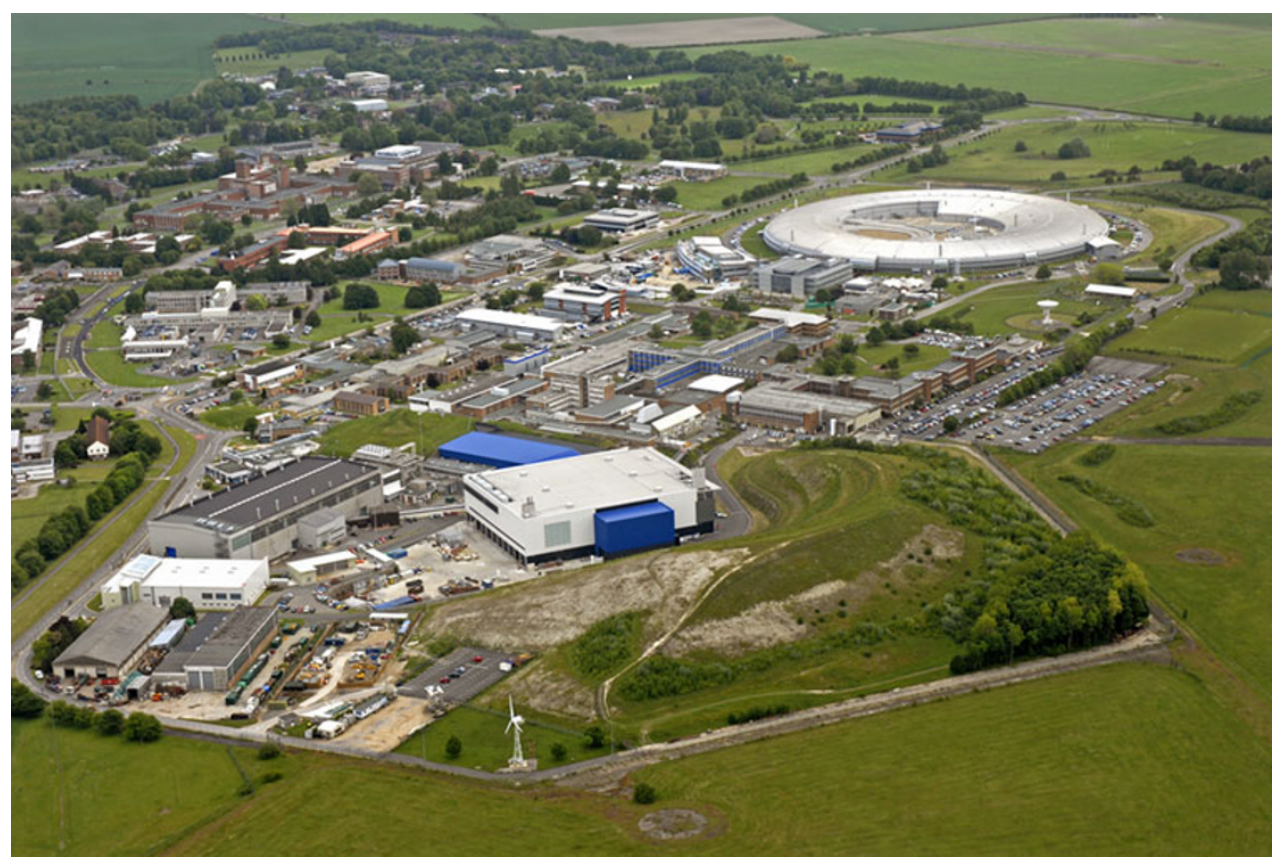

while incoherent scattering is a local probe. The neutron may be scattered without a change in energy (elastic scattering) as in diffraction, so this relies on $\sigma_{\text {coh }}$ or they may be exchange of energy between the sample and the neutron (inelastic scattering). The latter may be coherent or incoherent, but for any material containing hydrogen, the incoherent scattering dominates. For catalyst studies this is both a blessing and a curse. Since much of catalysis involves the transfer of hydrogen from reactant to product, for structural studies it is usually necessary to use deuterated materials. For inelastic scattering, it is only the exceptionally large value of $\sigma_{\text {inc }}$ that makes such studies feasible.

In the rest of the paper, we will describe the instruments that have been used for catalyst studies and the infrastructure that has been developed to enable such work. It must be emphasized that for successful investigations both components are essential.

\section{Elastic scattering}

Dedicated catalysis and gas handling systems for catalytic reaction have been developed at ISIS [37] to directly probe the structure of catalyst materials in environments that closely approximate those of real industrial processes. This apparatus permits catalysis samples to be studied within the elastic instruments at ISIS while under vacuum, flowing atmospheres of up to 5 bar and at temperatures between 4 and 1,273 K. In 2000, Turner et al. [36] utilized this apparatus to probe the interaction of the active site of a $\mathrm{NiNa}$-Zeolite $\mathrm{Y}$ catalyst (NiNaY) with acetylene. Here, two samples of $\mathrm{NiNaY}\left({ }^{\mathrm{Nat}} \mathrm{NiNaY}\right.$ and ${ }^{62} \mathrm{NiNaY}$ ) were analyzed using the small angle neutron diffractometer for liquids and amorphous samples (SANDALS) at ISIS together with the catalysis apparatus described above. The SANDALS diffractometer at ISIS has been specially constructed to investigate the structure of liquids and amorphous materials over a wide range $\left(0.2-50 \AA^{-1}\right)$ of momentum transfers and the combination of an intense pulsed neutron source and a large number of detectors at low angles make SANDALS particularly useful for measuring structure factors containing light atoms such as hydrogen and deuterium. Total neutron cross scattering was measured for the two NiNaY samples $\left({ }^{\mathrm{Nat}} \mathrm{Ni}\right.$ and $\left.{ }^{62} \mathrm{Ni}\right)$ with and without the addition of $d_{2}$-acetylene $\left(C_{2} D_{2}\right)$. For acetylene-free samples, a very clear differentiation of the isotopically enriched and natural abundance samples was obtained. When treated with deuterated acetylene the intermolecular $\mathrm{C}-\mathrm{C}$ and $\mathrm{C}-\mathrm{D}$ bond lengths could be observed at $r_{\mathrm{CC}}=1.16 \pm 0.01 \AA$ and $r_{\mathrm{CD}}=2.3 \pm 0.05 \AA$, with small changes to the host structure. The complementary use of density functional theory (DFT) modeling with the total scattering studies allowed the investigators to observe a considerable deformation of the acetylene, with the $\mathrm{C}-\mathrm{C}$ bond lengthening by $0.05 \AA$, and the $\mathrm{C}-\mathrm{D}$ bonds bending back from the coordinating metal centre by $11^{\circ}$, with a concomitant reduction in the charge of the nickel ion from +2 to +1.08 due to donation of electron density from the $\mathrm{C}-\mathrm{C}$ triple bond (Fig. 3). The neutron data were found to be consistent with structural features of the predicted $\mathrm{Ni}$ complex associated with the Dewar-Chatt-Duncanson model for $\pi$ acid coordination. Similarly, Parker et al. [25] have used a combination of inelastic and elastic neutron 
Fig. 2 Schematic plan of the of the ISIS facility

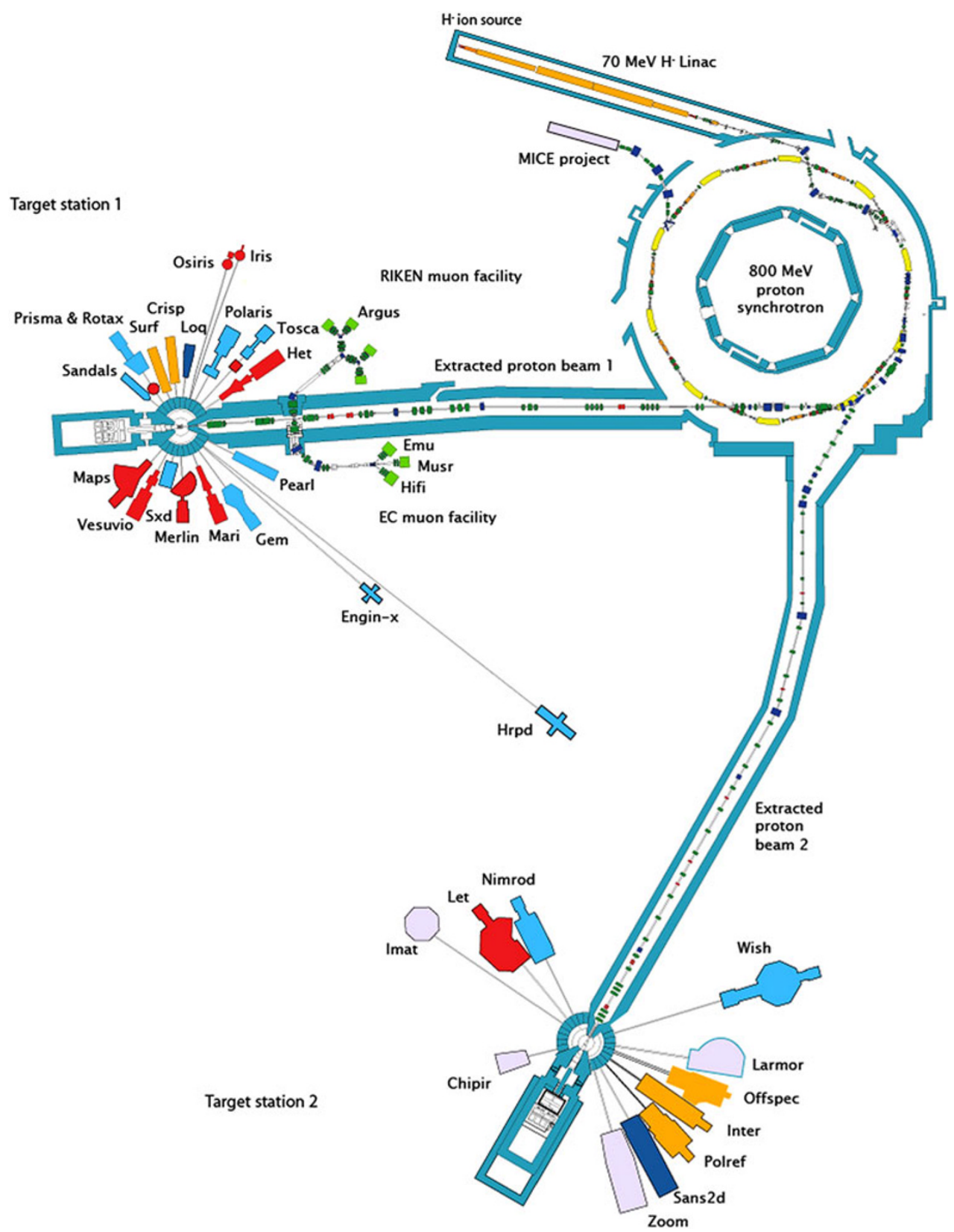

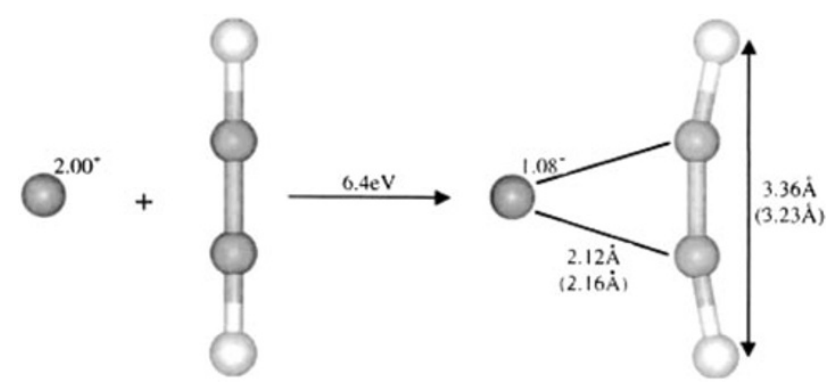

Fig. 3 Optimised geometries, Ni charge and binding energy for the interaction of one molecule of acetylene with a bare $\mathrm{Ni}^{\mathrm{II}}$ ion, from Turner [36] scattering techniques using the TOSCA and SANDALS instruments at ISIS, respectively, to investigate $\mathrm{Ni}-\mathrm{Ni}$ and $\mathrm{Ni}-\mathrm{H}$ distances of a RANEY nickel hydrogenation catalyst at 1 bar $\mathrm{H}_{2}$ and ambient temperature. Further combined inelastic and elastic neutron diffraction studies were performed by Parker et al. [26] on the model oxidation catalyst, hydrous palladium oxide. A combination of X-ray and neutron diffraction, inelastic neutron scattering, electron microscopy, infrared spectroscopy and periodic-DFT calculation were used to comprehensively characterize hydrous palladium oxide and identify it as a nanocrystalline material of general formula $\mathrm{PdO} \cdot \mathrm{H}_{2} \mathrm{O}$. Here, the 
GEneral Materials diffractometer (GEM) at ISIS was used to determine the structure of $\mathrm{PdO} \cdot \mathrm{H}_{2} \mathrm{O}$. The GEM diffractometer can perform high intensity, high resolution experiments to study the structure of disordered materials and crystalline powders. It utilizes a highly stable detector array, which covers a very wide range in scattering angle $\left(1.1^{\circ}-169.3^{\circ}\right)$ and a very large solid angle, leading to a wide dynamic range and a high count rate. The high real-space resolution of GEM approaches $0.1 \AA$ due to the high maximum momentum transfer $\left(55 \AA^{-1}\right)$ [9]. The GEM diffractometer also offers the capability of diffraction within a high temperature gas flow cell up to $1,300 \mathrm{~K}$ and a variety of atmospheres and gas flow rates (Figs. 4, 5, [10]). This apparatus, in conjunction with the GEM diffractometer, was used to investigate the structural properties of anion deficient ceria, $\mathrm{CeO}_{2-\delta}$, as a function of oxygen partial pressure. Here, analysis of the total scattering, together with reverse Monte Carlo (RMC) modeling highlighted preferential alignment of $\mathrm{O}^{2-}$ vacancies as pairs in the $<111>$ cubic directions as the degree of nonstoichiometry increased [11].

Purely structural analysis of catalysis materials may also be undertaken at ISIS. In 2002, Fowkes et al. [8] undertook a study of copper (II) and copper (I) exchanged zeolite Y

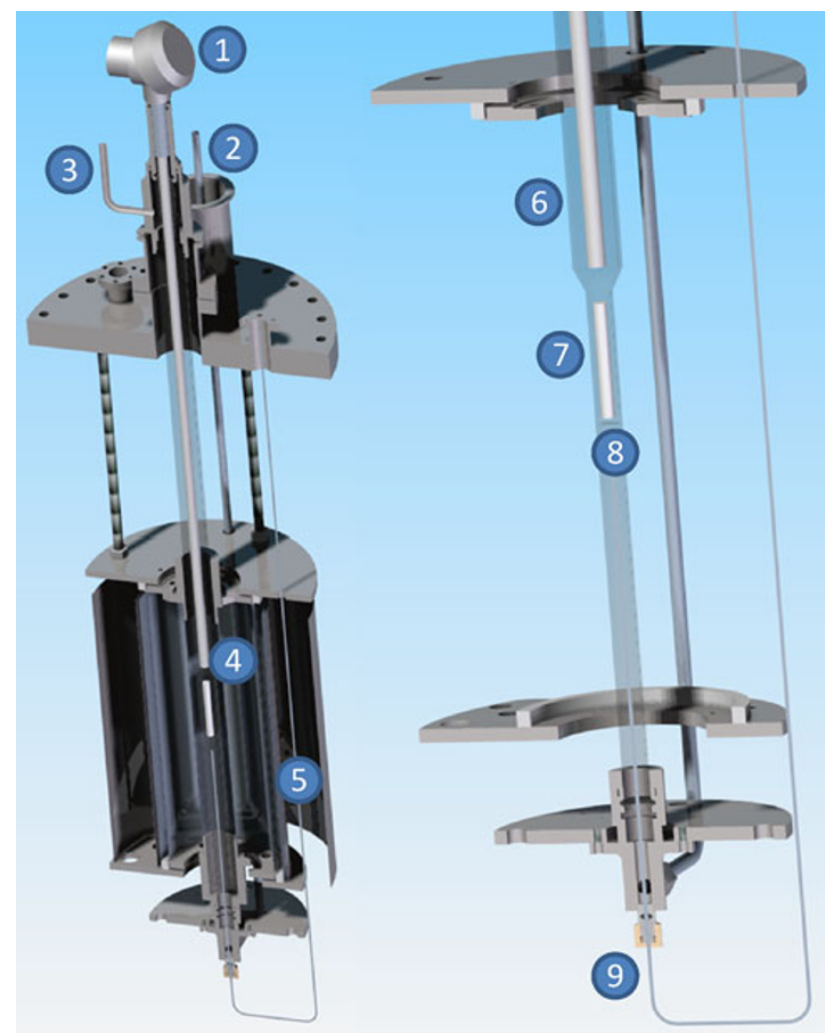

Fig. 4 The schematic diagram of the flow-through gas cell (with the right hand portion highlighting the central portion of the left hand figure), showing (1) oxygen and temperature sensor; (2) gas inlet; (3) gas outlet; (4) heater element; (5) heat shielding; (6) quartz sample holder; (7) sample; (8) quartz frit; (9) thermocouple, from [10]

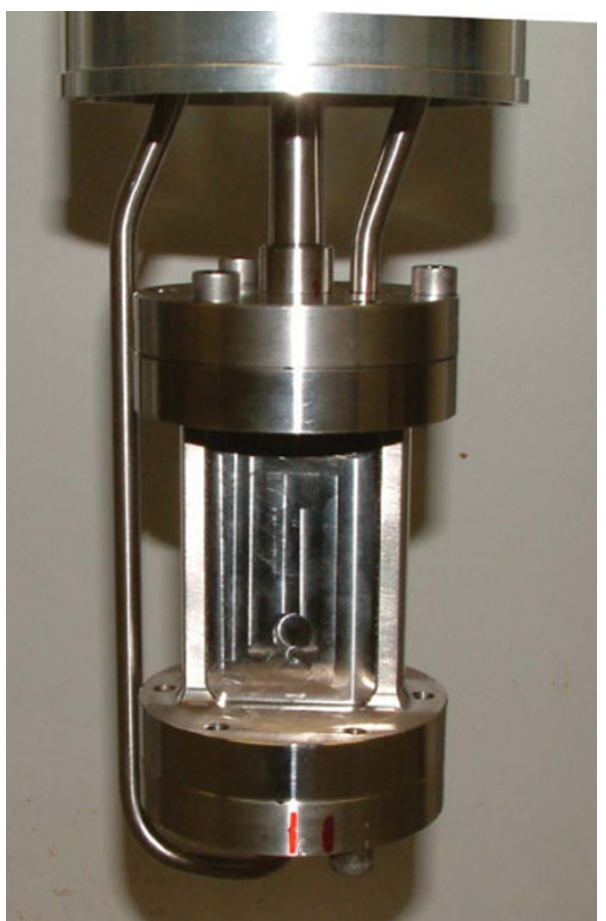

Fig. 5 The GEM diffractometer high temperature gas flow cell, capable of up to $1,300 \mathrm{~K}$ and a variety of atmospheres and gas flow rates

using the high resolution powder diffractometer (HRPD) at ISIS to reveal subtle changes in cation site occupancy, cation-framework interactions and framework relaxation. HRPD is the highest resolution neutron powder diffractometer of its type in the world with a main backscattering detector bank $\Delta \mathrm{d} / \mathrm{d}$ resolution of $\sim 4 \times 10^{-4}$, which allows resolution of peaks at d-spacings below $0.3 \AA$, and up to a maximum wavelength of 10-12 $\AA$. Potential catalysis materials, such as metal organic framework (MOF) materials have also been studied at ISIS and in 2010, Yan et al. [37] used the GEM diffractometer at ISIS to study the preferential absorption sites for $\mathrm{D}_{2}$ in the NOTT-115 and NOTT-116 MOF materials. High pressure diffraction studies may also be performed at ISIS using the PEARL diffractometer, which is a medium resolution high-flux diffractometer optimized for data collection from a ParisEdinburgh pressure cell, permitting structural studies to be carried out at pressures up to $25 \mathrm{GPa}$ and routinely up to $\sim 10 \mathrm{GPa}$ using ISIS tungsten carbide anvils. In 2005 , Colligan et al. [7] utilized this instrument to investigate the zeolite natrolite in mixtures of perdeuterated methanol and water at pressures of up to $1.87 \mathrm{GPa}$.

\section{Inelastic scattering}

Inelastic neutron scattering (INS) covers a large range of both energy (equivalent to the microwave to the vacuum 
ultraviolet) and timescales (micro- to attoseconds). In all cases it is the energy difference, $\Delta \mathrm{E}$, between the incident and the scattered neutron that is required. With quasielastic scattering, $\Delta \mathrm{E} \sim 0 \mathrm{~cm}^{-1}$, the applications include measurements of diffusion constants in microporous materials [15], or the temperature of dissociation of hydrogen on a surface [24]. At higher energies, $100 \leq \Delta \mathrm{E} \leq 4,000 \mathrm{~cm}^{-1}$, neutron vibrational spectroscopy [22] has been used for the investigation of adsorbates [2] ranging from the molecular [21] to highly disordered hydrocarbonaceous overlayers [34].

ISIS is uniquely well-equipped for neutron vibrational spectroscopy. The four principle instruments for molecular vibrational INS at ISIS are TOSCA [6], MAPS [19], MARI [20] and MERLIN [5] covering an energy range of $0-16,000 \mathrm{~cm}^{-1}$. For inelastic scattering, in addition to the total neutron flight time either the arrival time of the neutron at the sample (direct geometry spectrometer, MARI, MAPS and MERLIN) or the time for the neutron to travel from the sample to the detector must be known (indirect geometry spectrometer, TOSCA). This requires fixing either the incident energy or the final energy. TOSCA has a spectral range of $-24-4,000 \mathrm{~cm}^{-1}$ with a resolution of $\sim 1.25 \%$ of the energy transfer for transitions below ca. $1,200 \mathrm{~cm}^{-1}$ and a precision of $\sim 3 \mathrm{~cm}^{-1}$ below $2,000 \mathrm{~cm}^{-1}$. The direct geometry instruments provide the opportunity to trade sensitivity and resolution and MARI produces a monochromatic neutron beam in the range of $72-8,060 \mathrm{~cm}^{-1}$ with a resolution of $\sim 1 \%$ of the incident energy, $E_{\mathrm{i}}$, at the largest energy transfer. MAPS operates between 120 and $16,000 \mathrm{~cm}^{-1}$ with a resolution of up to $1.5 \% E_{\mathrm{i}}$, while MERLIN is a very high count rate, medium energy resolution, spectrometer operating in the range of $50-16,000 \mathrm{~cm}^{-1}$, with a resolution of $3-5 \% E_{\mathrm{i}}$. Both MAPS and MERLIN have a very large array of positionsensitive detectors, on MERLIN this is nearly $180^{\circ}$ in the horizontal plane and $\pm 30^{\circ}$ in the vertical plane, which provide high sensitivity for weakly scattering samples such as adsorbed species on catalysts. The two types of spectrometer are highly complementary [28], for modes at $<1,200 \mathrm{~cm}^{-1}$, TOSCA is the best resolution spectrometer in the world, while the direct geometry instruments are able to explore the $2,800-4,000 \mathrm{~cm}^{-1}$ region, where the characteristic $\mathrm{C}-\mathrm{H}, \mathrm{N}-\mathrm{H}$, and $\mathrm{O}-\mathrm{H}$ stretch modes occur.

INS spectroscopy is not intrinsically a surface sensitive technique, high penetration of neutrons means that all the atoms in the sample contribute to the signal. Since the number of surface atoms is usually only a small fraction of the total number of atoms present, it is essential to maximize the signal from the surface species. In practice, this means that adsorbates must be hydrogenous, large samples are needed and high surface area is required. Sample sizes are typically in the $10-50 \mathrm{~g}$ range, a 1000-fold larger than is typically used for microreactor studies. For commercial catalysts, the sample size is generally not a concern and has the advantage that representative sampling is much less of a problem. For research materials, generating sufficient sample for an INS study can be a challenge. A flexible system that is capable of producing the samples for a range of heterogeneously catalyzed reactions has been jointly developed between ISIS and the University of Glasgow (Fig. 6) [35]. The technology is essentially the same as that used for microreactor studies but scaled-up to handle the larger quantities of sample and reactants required. The system can treat up to $30 \mathrm{~g}$ quantities of catalyst under representative reaction conditions of up to $823 \mathrm{~K}$ and pressures of up to 20 bar. Furthermore, the modularity of the design allows adaptation of the apparatus to different reaction conditions. The penetrating nature of neutrons means that there is a wide choice of materials for sample cells. Steel, quartz, Inconel ${ }^{\mathrm{TM}}$ (a Ni(70\%)/Cr/Fe alloy with minor amounts of other elements) and Zircaloy ${ }^{\mathrm{TM}}$ (95\% $\mathrm{Zr}, \sim 2 \% \mathrm{Sn}$ and small amounts of $\mathrm{Nb}, \mathrm{Fe}, \mathrm{Cr}, \mathrm{Ni}$ ) cells have all been used in a wide variety of designs, including flow-through and batch reactors (Fig. 7).

Zeolites are among the most important catalyst materials, but below $\sim 1,800 \mathrm{~cm}^{-1}$ are opaque to infrared radiation; however, they are transparent to neutrons, thus the combination of INS to study the 'fingerprint region' with infrared spectroscopy to study the $\mathrm{O}-\mathrm{H}$ stretch region is very powerful and enables access to the complete $0-4,000 \mathrm{~cm}^{-1}$ spectral range. This has been used to characterize hydroxyls and ammonium ions in $\mathrm{Y}$ zeolite $[13,14]$

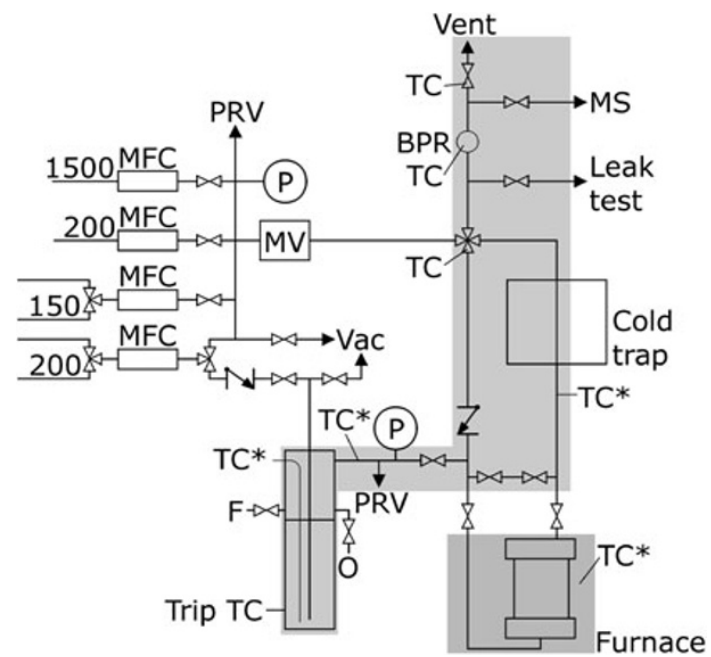

Fig. 6 Schematic of gas handling equipment showing arrangement of mass flow controllers [numbers indicate maximum flow rates for $\mathrm{N}_{2}$ $(\mathrm{sccm})]$, pressure relief valves $(P R V)$, pressure sensors $(P)$, mixing volume $(M V)$, vacuum connections (Vac), thermocouple (TC), fill and overflow saturator lines $(F$ and $O$ ), mass spectrometer $(M S)$, and back pressure regulator $(B P R)$. Shaded areas indicate heated gas lines. Reproduced from [35] 


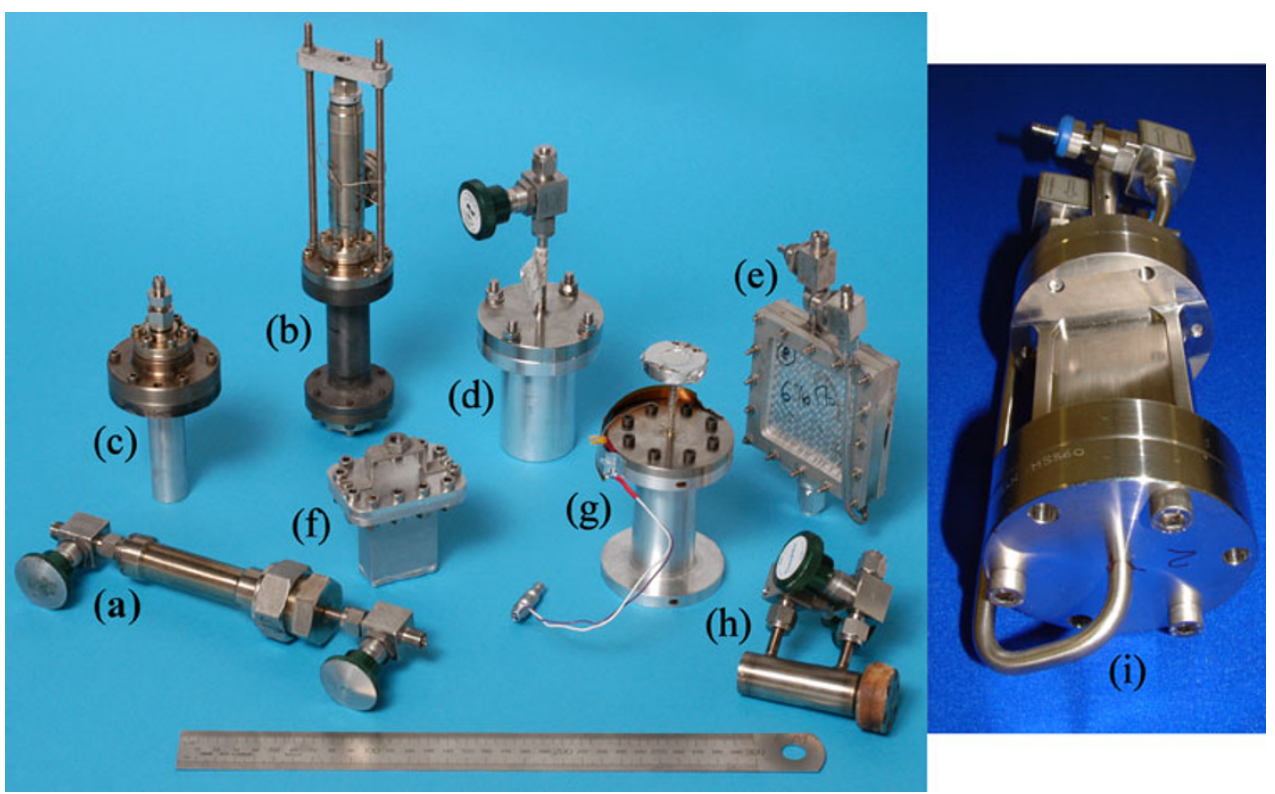

Fig. 7 Left vertically oriented catalyst cells as used on MAPS and TOSCA at ISIS: (a) high temperature $(>600 \mathrm{~K})$, flow-through, Swagelok $^{\mathrm{TM}}$ sealed stainless steel cell, $(b)$ high temperature gold wire sealed Zircaloy ${ }^{\mathrm{TM}}$ cell, $(c)$ low volume and $(d)$ high volume O-ring sealed aluminum cells for batch reactions, $(f)$ aluminum cell for off-line prepared samples, $(g)$ low temperature $(323 \mathrm{~K}<)$ indium

and also to investigate the adsorption of short carbon chain $\left(\mathrm{C}_{1}-\mathrm{C}_{4}\right)$ on cation-exchanged zeolite $\mathrm{X}[32,33]$. Using a combination of NMR, infrared and the TOSCA spectrometer at ISIS Schenkel et al. were able to identify the sorption structures for a number of $\mathrm{C}_{1}-\mathrm{C}_{4} n$-alcohols, the strongest adsorption sites and a rationale for the difference in sorption behavior for the different cation-substituted materials.

Determination of surface-adsorbed species is important for all catalyst materials, albeit for varying reasons. For example, pyridine chemisorption is often used as a probe of surface acidity usually in conjunction with infrared spectroscopy. The use of neutrons greatly extends the spectral window available and in addition to the study of pyridine on alumina [18], where it is routinely used, it has also been possible to study pyridine adsorption on activated carbon, which is often used as a support material for precious metal catalysts [17]. Adsorbed species on used catalysts are also of considerable industrial interest. An examination of a $20 \% \mathrm{Pd} / \mathrm{C}$ catalyst that had been used for Heck coupling reactions of bromobenzene and styrene to trans-stilbene produced the surprising result that the predominate surface species was $c i s$-stilbene, even though a yield of about $90 \%$ of trans-stilbene was measured in the product mixture [1].

In 2005, Lennon et al. with an industrial partner, carried out a combined infrared and INS study of the interaction of $\eta$-alumina and methanol using both the MARI and TOSCA spectrometers [21]. This reaction is important in the wire sealed aluminum cell, $(h)$ flow-through, Conflat ${ }^{\mathrm{TM}}$ sealed stainless steel cell for use on MARI at ISIS. The scale in the foreground is $0.3 \mathrm{~m}$. Right high pressure ( $20 \mathrm{bar}$ ), high temperature $(873 \mathrm{~K})$ Conflat $^{\mathrm{TM}}$ sealed Inconel ${ }^{\mathrm{TM}}$ cell [36] for use on MAPS or TOSCA. The overall length including valves and pipe work is $0.28 \mathrm{~m}$

industrial scale manufacture of methyl chloride, where methanol and hydrogen chloride are combined over high surface area alumina catalysts. The combination of TOSCA and MARI INS instruments permits both high (MARI) and low (TOSCA) energy modes to be observed, and thus the complete spectroscopic range from $0-4,000 \mathrm{~cm}^{-1}$ to be investigated at high resolution. This combination of techniques permitted the investigators to determine the dominant surface species to be an adsorbed methoxy species. One of the problems associated with methyl chloride synthesis is that dimethyl ether, $\mathrm{CH}_{3} \mathrm{OCH}_{3}$, is formed as an unwanted by-product. As a result of this work, the industrial partner was able to modify the surface properties of the catalyst so as to drastically reduce the amount of dimethyl ether produced and the attendant cost of recycling it back to methanol. This is a clear demonstration of chemical understanding at the molecular level helping to rationalise improvements in a large scale industrial process with both financial and environmental benefits.

Recent work has examined the Lindlar catalyst (leadmodified palladium on calcium carbonate) and compared it to an unmodified catalyst (palladium on calcium carbonate) [4]. The Lindlar catalyst is remarkable, because it selectively reduces alkynes to $c i s$-alkenes whereas the unmodified catalyst results in alkanes. The MAPS spectrometer is particularly suited to the study of supported catalysts as its enhanced sensitivity permits the study of the low concentrations of precious metal catalysts often found in 
commercial catalyst materials. Similar studies have been carried out by Ramirez-Cuesta et al. [30, 31] looking at zeolitic materials, Larese et al. [16] looking at binding of $\mathrm{H}_{2}$ onto $\mathrm{MgO}$ and Albers et al. [3] looking at carbonsupported platinum-ruthenium fuel cell catalysts.

Reforming of methane to syngas $\left(\mathrm{CO} / \mathrm{H}_{2}\right)$ is an important industrial process and the study of reforming catalysts, typically nickel/alumina, is of significant interest. However, deactivation by carbon build-up is a major problem. Utilizing the apparatus previously described (Fig. 6), a series of deactivated catalysts were prepared. Operating the MAPS spectrometer at an incident energy of $4,840 \mathrm{~cm}^{-1}$ to focus on the crucial $\mathrm{C}-\mathrm{H}$ and $\mathrm{O}-\mathrm{H}$ spectral region, Silverwood et al. [34] were able to identify the extent of overall carbon laydown on the catalyst and also to quantify the hydrogen associated with carbon and oxygen. This ability to quantify surface species is a unique capability of INS spectroscopy.

INS measurements are usually carried out at low temperature, $<20 \mathrm{~K}$. However, in favorable circumstances, by taking advantage of the capabilities of the MAPS spectrometer, it is possible to carry out in operando experiments. In an example of this, experiments were carried out in MAPS at room temperature under flowing $5 \% \mathrm{CO} / \mathrm{He}$ $\left(100 \mathrm{~cm}^{3} \mathrm{~min}^{-1}\right)$ to investigate the low temperature oxidation of carbon monoxide over hydrous palladium oxide. This work identified that the active phase of $\mathrm{PdO}$ for $\mathrm{CO}$ oxidation is closely associated with hydroxyl groups [27].

To understand catalytic processes, it is often necessary to use model compounds and completely characterize the reactants and products. For these types of study TOSCA excels due to its spectral range and high resolution and has been used to study ethylidyne tricobalt nonacarbonyl [23], a model compound for the adsorbed ethylidyne that results from hydrogenation of ethene on (111) surfaces. Parker et al. [29] also recently completed a combined, simultaneous infrared and INS study of the C5 dienes and alkenes that result from hydrogenation of a $\mathrm{C} 5$ mixture over a $\mathrm{Pd} / \mathrm{Al}_{2} \mathrm{O}_{3}$ catalyst. The mixture models a $\mathrm{C} 5$ raffinate cut from a refinery. In this study Parker et al. were able to compare INS, Raman and infrared spectra with calculated spectra for a number of species, and were able to show that the combination of spectroscopic techniques provided data that could be used for quantifiable, real-time gas-phase catalysis processes as well as molecular, isomer and conformer discrimination.

\section{Conclusion}

It can be seen that the use of neutron scattering techniques, either on their own, or in conjunction with other techniques can provide a range of information on catalysts and catalytic systems that is not available through the sole use of other, more routine, spectroscopic techniques. The large spectral range of the ISIS spectrometers, high resolution of ISIS diffractometers and high neutron cross section of hydrogen make ISIS a unique and world-leading facility for the study of catalysts and catalytic processes. The recent development of gas handling and specialist sample environments now allows scientists to test industrially relevant samples in environments that exactly mimic or closely approach those utilized in commercial processes. These in operando studies significantly increase the relevance of neutron scattering studies, permitting scientists to directly investigate commercially important processes and thus develop a greater understanding of catalytic mechanisms and processes, and thus produce catalysts and catalytic processes with enhanced properties.

Open Access This article is distributed under the terms of the Creative Commons Attribution License which permits any use, distribution, and reproduction in any medium, provided the original author(s) and the source are credited.

\section{References}

1. Albers PW, Krauter JGE, Ross DK, Heidenreich RG, Kohler K, Parker SF (2004) Identification of surface states on finely divided supported palladium catalysts by means of inelastic incoherent neutron scattering. Langmuir 20:8254-8260. doi:10.1021/ la040054c

2. Albers PW, Parker SF (2007) Inelastic incoherent neutron scattering in catalyst research. Adv Catal 51:99-132

3. Albers PW, Weber W, Kunzmann K, Lopez M, Parker SF (2008) Characterisation of carbon supported platinum-ruthenium fuel cell catalysts of different degree of alloying. Surf Sci 602: 3611-3616. doi:10.1016/j.susc.2008.10.006

4. Albers PW, Möbus K, Frost CD, Parker SF (2011) Characterization of $\beta$-palladium hydride formation in the Lindlar catalyst and in carbon-supported palladium. J Phys Chem C 115:2448524493. doi: $10.1021 /$ jp205951c

5. Bewley RI, Eccleston RS, McEwen KA, Hayden SM, Dove MT, Bennington SM, Treadgold JR, Coleman RLS (2006) RLS MERLIN, a new high count rate spectrometer at ISIS. Physica B 385-386:1029-1031. doi:10.1016/j.physb.2006.05.328

6. Colognesi D, Celli M, Cilloco F, Newport RJ, Parker SF, RossiAlbertini V, Sacchetti F, Tomkinson J, Zoppi M (2002) TOSCA neutron spectrometer; the final configuration. Appl Phys A 74(Suppl.):S64-S66

7. Colligan M, Lee Y, Vogt T, Celestian AJ, Parise JB, Marshall WG, Hriljac JA (2005) High-pressure neutron diffraction study of superhydrated natrolite. J Phys Chem B 109:18223-18225. doi: 10.1021/jp054142x

8. Fowkes AJ, Ibberson RM, Rosseinsky MJ (2002) Structural characterization of the redox behavior in copper-exchanged sodium zeolite $\mathrm{Y}$ by high-resolution powder neutron diffraction. Chem Mater 14:590-602. doi:10.1021/cm010504b

9. Hannon AC (2005) Results on disordered materials from the GEneral Materials diffractometer, GEM, at ISIS. Nucl Instrum Methods Phys Res A 551:88-107

10. Haynes R, Norberg ST, Eriksson SG, Chowdhury MAH, Goodway CM, Howells GD, Kirichek O, Hull S (2010) New high

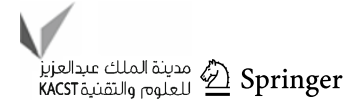


temperature gas flow cell developed at ISIS. J Phys Conf Ser 251:012090. doi:10.1088/1742-6596/251/1/012090

11. Hull S, Norberg ST, Ahmeda I, Eriksson SG, Marrocchelli D, Madden PA (2009) Oxygen vacancy ordering within aniondeficient ceria. J Solid State Chem 182:2815-2821. doi:10.1016/ j.jssc.2009.07.044

12. ISIS (2012) http://www.isis.stfc.ac.uk

13. Jacobs WPJH, van Santen RA, Jobic H (1994) Inelastic neutron scattering study of $\mathrm{NH}_{4} \mathrm{Y}$ zeolites. J Chem Soc Faraday Trans 90:1191-1196

14. Jacobs WPJH, van Wolput JHMC, van Santen RA, Jobic H (1994) A vibrational study of the OH and OD bending modes of the Brönsted acid sites in zeolites. Zeolites 14:117-125

15. Jobic H, Theodorou DN (2007) Quasi-elastic neutron scattering and molecular dynamics simulation as complementary techniques for studying diffusion in zeolites. Microporous Mesoporous Mater 102:21-50. doi:10.1016/j.micromeso.2006.12.034

16. Larese JZ, Arnold T, Frazier L, Hinde RJ, Ramirez-Cuesta AJ (2008) Direct observation of $\mathrm{H}_{2}$ binding to a metal oxide surface. Phys Rev Lett 101:165302. doi:10.1103/PhysRevLett.101.165302

17. Lennon D, Lundie DT, Jackson SD, Kelly GJ, Parker SF (2002) Characterization of activated carbon using X-ray photoelectron spectroscopy and inelastic neutron scattering spectroscopy. Langmuir 18:4667-4673. doi:10.1021/la011324j

18. Lundie DT, McInroy AR, Marshall R, Winfield JM, Mitchell C, Dudman CC, Jones P, Parker SF, Lennon D (2005) An improved description of the surface acidity of eta-alumina. J Phys Chem B 109:11592-11601

19. MAPS (2012) http://www.isis.stfc.ac.uk/instruments/maps/

20. MARI (2012) http://www.isis.stfc.ac.uk/instruments/mari

21. McInroy AR, Lundie DT, Winfield JM, Dudman C, Jones P, Parker SF, Taylor JW, Lennon D (2005) An infrared and inelastic neutron scattering spectroscopic investigation on the interaction of $\eta$-alumina and methanol. Phys Chem Chem Phys 7:3093-3101

22. Mitchell PCH, Parker SF, Ramirez-Cuesta AJ, Tomkinson J (2005) Vibrational spectroscopy with neutrons: with applications in chemistry, biology, materials science, and catalysis. World Scientific, Singapore

23. Parker SF, Marsh NA, Camus LM, Whittlesey MK, Jayasooriya UA, Kearley GJ (2002) Ethylidyne tricobalt nonacarbonyl: infrared, FT-Raman, and inelastic neutron scattering spectra. J Phys Chem A 106:5797-5802. doi:10.1021/jp014667z

24. Parker SF, Frost CD, Telling M, Albers P, Lopez M, Seitz K (2006) Characterisation of the adsorption sites of hydrogen on $\mathrm{Pt} / \mathrm{C}$ fuel cell catalysts. Catal Today 114:418-421

25. Parker SF, Bowron DT, Imberti S, Soper AK, Refson K, Lox ES, Lopez M, Albers P (2010a) Structure determination of adsorbed hydrogen on a real catalyst. Chem Comm 46(17):2959-2961. doi: $10.1039 / \mathrm{c} 001779 \mathrm{e}$
26. Parker SF, Refson K, Hannon AC, Barney ER, Robertson SJ, Albers P (2010b) Characterization of hydrous palladium oxide: implications for low-temperature carbon monoxide oxidation. J Phys Chem C 114:14164-14172. doi:10.1021/jp103847d

27. Parker SF (2011) The role of hydroxyl groups in low temperature carbon monoxide oxidation. Chem Commun 47:1988-1990. doi: $10.1039 / \mathrm{c} 0 \mathrm{cc} 04991 \mathrm{c}$

28. Parker SF, Lennon D, Albers PW (2011) Spectroscopy with neutrons: a review of new directions. Appl Spectrosc 65:1325-1341. doi:10.1366/11-06456

29. Parker SF, Siegel D, Hamilton NG, Kapitan J, Hecht L, Lennon D (2012) Characterization of C5 hydrocarbons relevant to catalysis. J Phys Chem A 116:333-346. doi:10.1021/jp209417d

30. Ramirez-Cuesta AJ, Mitchell PCH, Ross DK, Georgiev PA, Anderson PA, Langmie HW, Book D (2007) Dihydrogen in zeolite $\mathrm{CaX}$-an inelastic neutron scattering study. J Alloy Compd 446-447:393-396. doi:10.1016/j.jallcom.2006.12.030

31. Ramirez-Cuesta AJ, Mitchell PCH, Ross DK, Georgiev PA, Anderson PA, Langmie HW, Book D (2007) Dihydrogen in cation-substituted zeolites $\mathrm{X}$-an inelastic neutron scattering study. J Mater Chem 17:2533-2539. doi:10.1039/b701167a

32. Schenkel R, Jentys A, Parker SF, Lercher JA (2004ba) Investigation of the adsorption of methanol on alkali metal cation exchanged zeolite $\mathrm{X}$ by inelastic neutron scattering. J Phys Chem B 108:7902-7910

33. Schenkel R, Jentys A, Parker SF, Lercher JA (2004b) INS and IR and NMR spectroscopic study of $\mathrm{C} 1-\mathrm{C} 4$ alcohols adsorbed on alkali metal-exchanged zeolite X. J Phys Chem B 108:1501315026. doi:10.1021/jp047998v

34. Silverwood IP, Hamilton NG, Laycock CJ, Staniforth JZ, Ormerod RM, Frost CD, Parker SF, Lennon D (2010) Quantification of surface species present on a nickel/alumina methane reforming catalyst. Phys Chem Chem Phys 12:3102-3107. doi:10.1039/ B919977B

35. Silverwood IP, Hamilton NG, McFarlane A, Ormerod RM, Guidi T, Bones J, Dudman MP, Goodway CM, Kibble M, Parker SF, Lennon D (2011) Experimental arrangements suitable for the acquisition of inelastic neutron scattering spectra of heterogeneous catalysts. Rev Sci Inst 82:034101. doi:10.1063/1.3553295

36. Turner JFC, Done R, Dreyer J, David WIF, Catlow CRA (1999) On apparatus for studying catalysts and catalytic processes using neutron scattering. Rev Sci Instrum 70:2325. doi:10.1063/ 1.1149758

37. Yan Y, Telepeni I, Yang SH, Lin X, Kockelmann W, Dailly A, Blake AJ, Lewis W, Walker GS, Allan DR, Barnett SA, Champness NR Schroder M (2010) Metal-organic polyhedral frameworks: high $\mathrm{H}-2$ adsorption capacities and neutron powder diffraction studies. JACS 132:4092. doi:10.1021/ja1001407 